\title{
Lepidic Predominant Adenocarcinoma
}

National Cancer Institute

\section{Source}

National Cancer Institute. Lepidic Predominant Adenocarcinoma. NCI Thesaurus. Code C123160.

A lung adenocarcinoma characterized by the presence of mildly and moderately differentiated adenocarcinoma cells across the alveolar walls with at least one focus of invasive carcinoma measuring more than $5 \mathrm{~mm}$ in greatest dimension. 